\title{
Ergonomics Certification Update
}

\author{
VALERIE J. RICE \\ Occupational Physiology Division, U.S. Army Research Institute of Environmental Medicine, \\ Natick, Massachusetts
}

This article is an information update on issues in ergonomics. Ergonomic certification is currently being conducted by the Board of Certification in Professional Ergonomics. Ergonomic certification is also being discussed by health care professionals and has been addressed by the National Interdisciplinary Committee on Health Ergonomics. The activities of each organization are presented.

Keywords: Ergonomics; Certification; Health care

As those of you who have been keeping up with ergonomics certification are aware, a certification process exists. The group responsible for this process is the Board of Certification in Professional Ergonomics (BCPE). The possibility of a second certification process, specifically for health care professionals, has also been addressed (Hart, Isernhagen, and Matheson, 1993; Rice and Jacobs, 1993). This is a brief update on both of those issues.

\section{BCPE}

As of July 23, 1993, the BCPE had received 141 applications and issued 80 certificates for professional ergonomics and 20 certificates for human factors professionals. At the midyear meeting in May 1993, a test development working group was established and the evaluator panel was expanded to include nine individuals beyond the BCPE directors. A semiannual newsletter, The Professional Ergonomist (first issue, October 1993), and the first Directory of BCPE Certificants were authorized.

The certification criteria as of January 1, 1994, were identified and will be as follows:
- Education: Master's degree in ergonomics (human factors) or equivalent educational background in the life sciences, engineering sciences, or natural sciences to comprise ergonomics.

- Professional experience: Four years of fulltime-equivalent professional practice in ergonomics with emphasis on ergonomic design (in contrast to research, therapy, rehabilitation, and/or human behavior/functional assessment).

- Work product/example: Demonstration of having applied ergonomics data, methods, and/or principles to a technological product, process, or environment.

- Written examination: Passing score on the written examination developed and administered by the BCPE.

\section{HEALTH CARE}

A group of 15 health care practitioners met on July 30-31, 1993, in Minneapolis to discuss ergonomics as it applies to health care practitioners, including those specializing in ergonomic worksite analysis and intervention as well as those involved in ergonomic intervention on a limited 
basis. Although certification was addressed, no definitive stand was made on the issue at that time. The group chose the following name: the National Interdisciplinary Committee on Health Ergonomics (NICHE). During the meeting, the following was accomplished:

- Survey results (conducted by the Ergonomic Rehabilitation Research Society, Inc.) on ergonomics courses included in entry-level occupational and physical therapy curriculums were reviewed.

- Roles accomplished by health ergonomists during job analysis and intervention, as well as medical management of occupational/cumulative trauma injuries, were defined.

- Educational requirements commensurate with roles defined above were identified.

- It was noted that ergonomic job analysis and worksite intervention are beyond the basic knowledge and skills of entry-level occupational and physical therapists.

The roles defined and requirements identified will be printed in final form and distributed, along with an introductory paper stating the purpose, to various organizations for review and comment. It is hoped that each organization will respond with a statement of either support or nonsupport for a certification process. Reviewers will include the American Occupational Therapy Association, American Physical Therapy Association, American Industrial Hygiene Association, American Nursing Association, Human Factors and Ergonomics Society, and others. The results of the review will be the primary impetus for whether a certification process will be further explored. Therefore, it is important that individuals who have strong opinions either for or against certification inform representatives of their organizations. The group will also look for opportunities to publish the document to inform health care practitioners and invite their comments.

\section{REFERENCES}

Hart, D. L., Isernhagen, S. J., and Matheson, L. N. (1993). Refining the practice of ergonomics. Work, 3, 69-72.

Rice, V. J., and Jacobs, K. (1993). Ergo, you're legit: Credentialing in ergonomics. Rehabil Manag, 6, 3943. 